ARTICLE

https://doi.org/10.1057/s41599-019-0307-9

\title{
Inference from absence: the case of archaeology
}

\author{
Efraim Wallach ${ }^{1}$
}

\begin{abstract}
Inferences from the absence of evidence to something are common in ordinary speech, but when used in scientific argumentations are usually considered deficient or outright false. Yet, as demonstrated here with the help of various examples, archaeologists frequently use inferences and reasoning from absence, often allowing it a status on par with inferences from tangible evidence. This discrepancy has not been examined so far. The article analyses it drawing on philosophical discussions concerning the validity of inference from absence, using probabilistic models that were originally developed to show that such inferences are weak and inconclusive. The analysis reveals that inference from absence can indeed be justified in many important situations of archaeological research, such as excavations carried out to explore the past existence and time-span of sedentary human habitation. The justification is closely related to the fact that archaeology explores the human past via its material remains. The same analysis points to instances where inference from absence can have comparable validity in other historical sciences, and to research questions in which archaeological inference from absence will be problematic or totally unwarranted.
\end{abstract}

\footnotetext{
${ }^{1}$ The Hebrew University of Jerusalem, Jerusalem, Israel. Correspondence and requests for materials should be addressed to E.W. (email: efraim.wallach@mail.huji.ac.il)
} 


\section{Introduction}

'Argumentum ad ignorantiam ... is fallacious in every context but one. The exception is the court of law, where the guiding principle is that a person is presumed innocent until proven guilty' (Copi, 1953)

'Now, and with considerably more information on the presence and/or absence of domestic/managed animals from archaeological sites ... I reassess the zooarchaeological evidence for domestic animal introductions with some of the earliest proposed agricultural communities in the region' (Piper, 2017)

D.

he argument for or against a hypothesis from lack of evidence to something-known interchangeably as "argument from ignorance," "argument from silence," or "inference from absence" 1,2 has a bad reputation in epistemology. The maxim "Absence of evidence is not evidence of absence" was popularised by Carl Sagan ${ }^{3}$ (Sagan and Druyan, 1997, p. 213), but the concept probably dates back to antiquity. Locke (1690) categorised arguments from lack of evidence as dialectical rather than epistemic, and a Jewish religious ruling from the second century $\mathrm{AD}^{4}$ states that even when offered by an expert, such an argument is unacceptable.

Nevertheless, people often infer and argue from the absence of evidence in everyday life: "I don't see her car in the parking lot, so she must be elsewhere." "We know that Saddam Hussein did not possess weapons of mass destruction, since inspectors did not find any." In the sciences, however, inference from absence is usually considered invalid, or at best weak and inconclusive. Section "Why science (usually) won't take no for an answer" demonstrates this attitude and examines the difference between science and everyday discourse in this respect. A necessary condition for inference from absence of evidence to have a respectable plausibility is that the evidence is highly expected, a situation that is not uncommon in quotidian discourse but hard to come by in scientific research.

In archaeology, however, inference-from-absence arguments are quite common, as the examples in the next section demonstrate. Inferences for the timing of past events, processes, and state of affairs, either in the form of terminus ad quem or of terminus post quem (a date before or after which something happened or existed), often depend crucially on the absence of evidence from a particular period. Under certain conditions archaeologist even make-and accept-inferences not only from absence but also from a paucity of evidence, rejecting single or just-a-few traces as intrusive or residual (belonging to a later or earlier period than the context under investigation) and therefore inconsequential.

This exceptional prevalence of inference from absence in archaeology has so far escaped the notice of archaeologists and philosophers. The question that this article intends to examine is: Is this practice justified, or is it just scandalous negligence of sound logical principles?

As shall be shown below, there is indeed dissimilarity in this respect between archaeology and other sciences, including disciplines (such as palaeontology and historiography) that are considered comparable or close to archaeology. The dissimilarity stems from characteristics that pertain to the nature of archaeology as a discipline that seeks to reconstruct the human past via its material remains.

As shall be discussed in Section "The distinctiveness of archaeology", both elements-human past activity and material traces thereof-are of import here. It is their combination that creates situations in which evidence is highly expected, and therefore, its absence is highly significant. This explains why archaeologists often accept such inferences as legitimate-though of course, not infallible-arguments. In other historical sciences similar situations, though possible, are much less common.

Section "The distinctiveness of archaeology" presents this argument in details, and section "A probabilistic model" explores the same issue through a probabilistic model adopted from Sober (2009) and McGrew (2014). Section "Limitations of archaeological inference from absence" discusses some limitations to archaeological inference from absence. Although useful and legitimate for addressing several important questions about the human past, there are conditions under which it can be problematic or entirely inapplicable. Section "Only in archaeology?" uses the same analysis to identify circumstances favourable for inference from absence in other historical sciences. The last section summarises the argument and concludes with some general remarks.

\section{Inference from absence in archaeology}

Below are several examples of how archaeologists use inference from absence in their work:

i. A review (Roebroeks and Villa, 2011) of evidence for the use of fire by early humans in Europe supported a conclusion that habitual use of fire did not emerge there until the second half of the Middle Pleistocene, 300-400 thousand years ago.

This result is surprising, given the climatic conditions in northern latitudes. The authors maintain, however, that it is solid: "Cave sequences spanning the latter part of the Early Pleistocene and the earlier part of the Middle Pleistocene in Europe do not have convincing evidence of fire. The number and quality of these early sites are significant, and this absence of evidence cannot be ignored."

ii. Hypotheses about the timing and the dispersion routes of early hominins from Africa to Eurasia and beyond are supported not only by the presence but also by the absence of human material remains. Chronological gaps in the sequences of fossils and artefacts point to several waves of colonisation, as well as to extinctions of some early migratory lineages (Bar-Yosef and Belfer-Cohen, 2001; López et al., 2015). Similarly, gaps in the archaeological record in Middle Palaeolithic sites in Northwestern Europe (Hublin and Roebroeks, 2009) are interpreted as hiatuses in human presence, probably due to interspersed regional extinction.

iii. Archaeological investigations of the origins and dispersal of agriculture rely on inference from absence to determine the earliest appearance of domesticated plants and animals in various regions.

Several factors, like the perishability of organic material (cf. section "Limitations of archaeological inference from absence") and the difficulty of distinguishing between wild and domesticated strains, make such determinations difficult. Nevertheless, evidence for absence of domesticated strains in archaeological sites plays an important and sometimes crucial role in the formulation and adjudication of hypotheses about the timing and origins of Neolithization.

The recognition that "the striking fact remains that the Nile Valley cannot be demonstrated to have been settled by agriculturalists until about 5500-5000 BC" (Bellwood, 2005) put an end to the once-popular theory (Childe, 1934, pp. 49-84) that pre-dynastic Egypt was the locus of the earliest agriculturalists. Remarkably, absolute absence is not always mandatory for such arguments. For example, Fuller (2006, p. 16) deduced from "the (near) ${ }^{5}$ absence of wheat and barley" in certain archaeological deposits in the Indus valley that these cereals "may only have been imported to certain 
townsites ... Although wheat is a significant crop in the region today, this must have developed in post-Harappan times."

iv. In the early 1930s, a young archaeologist stunned her colleagues (as well as many laymen) when she reported (Marquet-Krause, 1934, 1935) that her excavations at the mound of Et-Tell in Palestine, generally recognised as the site of biblical $\mathrm{Ai}$, did not expose material remains from the Middle Bronze or Late Bronze Ages (but only from earlier and later periods). These results were sufficient to convince many contemporary scholars that the events detailed in Jos. 7-8 did not happen. Thirty years later, an expanded excavation by another archaeologist (Callaway, 1968) at the same site confirmed Marquet-Krause's conclusion and his soundings at several alternative locations for biblical $\mathrm{Ai}$ showed, by similar evidence-from-absence arguments, that none of them was inhabited in the relevant period.

Actually, Marquet-Krause (1934) mentioned finding a few sherds that might belong to the Middle Bronze Age, and another archaeologist (Garstang, 1931) reported finding a Late Bronze potsherd there. As more data from the site was gathered, however, these finds were deemed singular, out-of-context and, therefore, irrelevant.

v. Reviewing archaeological findings from sites mentioned in the Egyptian execration texts dated to Middle Bronze IIA, Ben-Tor (2006) noted that in quite a few of them "No major public construction datable to MB IIA was encountered... not one of them was fortified." He concluded that these texts could not provide reliable information on the inhabitation map, or the Egyptian involvement, in the Western Levant at that period. To explain the discrepancy, he suggested that the placenames in the texts were copied from similar ones written in an earlier period - an instance of ancient fake news.

vi. In his seminal article "The Date of the Settlement of the Philistines in Canaan" Finkelstein (1995) suggested that this date should be lowered by about half a century. This inference is derived from the absence of sherds of locally made Philistine ware, and specifically of the early (monochrome) type, in strata that yielded traces from the reign of Ramses III. ${ }^{6}$ Since the distinctive Philistine ceramics are often used to date strata in other sites, these conclusions have far-reaching historiographical implications. Scholars (e.g., Mazar, 1997) who rejected Finkelstein's suggestion did not dispute the "evidence from absence" in itself, but what it is evidence for. The lack of Philistine material remains in particular strata, they argued, is evidence of a territorial, demographic, and cultural separation rather than of a chronological one.

vii. The absence of zooarchaeological as well as artistic evidence of domesticated camels in the southern Levant during the Bronze Age prompted even a conservative scholar like W.F. Albright (1940, p. 196; 1968), who famously strived to establish the historicity of the biblical narratives, to conclude that early biblical references to camels (e.g., Gen. 24) were anachronistic. Modern research reconfirmed this conclusion, again using a form of evidence from absence. Sapir-Hen and Ben-Yosef (2013) report that in the Araba valley in Israel "camel bones in substantial quantities appear only in contexts dated to the last third of the 10th century" and conclude that this enables "to pinpoint the introduction of camels to the Southern Levant" to this time.

The wording "in substantial quantities" is significant here. A single bone fragment from a lower stratum (Sapir-Hen and BenYosef, 2013, p. 279n) was considered insufficient to change the conclusion.
These examples demonstrate that inference and argumentation from absence and from paucity play an important role in archaeology. Notwithstanding the adage "absence of evidence is not evidence of absence," archaeologists often advance, debate and accept inference from absence in a way that is exceptional when compared to other sciences.

This does not imply, of course, that archaeological inference from absence will always be correct. Like any empirical inference, it is fallible and can be revised in light of later discoveries or further analysis. The point is, rather, that archaeology often treats inference from absence of evidence as legitimate and comparable to inference from tangible evidence. The question addressed below is whether this practice is epistemically sound.

\section{Why science (usually) won't take no for an answer}

Speaking of the ability of the historical sciences to inform us about the past, Sober (1988) observed that

the knowability of the past depends on whether the physical processes linking past to present are information preserving or information destroying; this cannot be known a priory, but depends on the specific processes at work and on data available to the scientist.

Turner (2007, p. 53) pointed out that adverse situations are more common:

many historical processes-the fossilisation process, the processes of weathering and erosion, continental drift, subduction, glaciation, and so on-are informationdestroying processes, rather like housecleaning and document shredding.

This irretrievable loss of information is, according to Turner, one reason to expect that hypotheses about the past will usually be strongly underdetermined (our inability to manipulate the past, which does not concern us here, is another). ${ }^{7}$

In a recent book Currie (2018) elaborates on this observation by introducing a "ripple model" for the survival and usability of traces of past event and state-of-affairs: Normally, such traces are progressively degraded, both qualitatively and quantitatively, after their creation. The remaining record will suffer from "gappiness" when traces are destroyed, and also from "faintness" which is the result of both the relative difficulty of locating extant traces and of linking them to past events.

Ceteris paribus, faintness increases through time. Ceteris paribus, gappiness increases through time. Ceteris paribus, the higher the faintness or gappiness of an event's traces, the less retrievable the event. As time goes by, information about past events degrades to the point of erasure (p. 121).

Currie characterises such situations as "unlucky circumstances": "Events in the past with high gappiness and faintness, unless offset by high dispersal, will have a low retrievability" (p. 125). His main objective is to demonstrate that scientists can and do deliver worthwhile "epistemic goods" which may include -but are not limited to-truths about the past, but he agrees that lack of evidence is restrictive: "an absence of traces can occasionally distinguish between historical hypotheses, but this is tricky. Sober (2009) has a nice probabilistic discussion of just this point."

Scientific inferences from absence are usually treated as problematic, if not outright fallacious. Here are some examples to this attitude, with particular attention to disciplines that, like archaeology, use extant traces to support reconstructions of past events and circumstances: 
i. Sober (2009), mentioned above, analysed inference from absence in palaeontology and evolutionary biology. Using a probabilistic model (to be explored in section "A probabilistic model") Sober showed that inferences of separate ancestry from the failure to find intermediate forms in the fossil record, though valid in principle, are very weak. Forber and Griffith (2011) used the same model to show that the disappearance of a taxon from the fossil record close to a mass extinction event is insufficient to prove that the taxon perished at this event, rather than at some prior time. Cleland (2013) asserts that the opposite is also true: "Failure to find ammonite fossils sufficiently close to the lower level of the $\mathrm{K}-\mathrm{Pg}$ boundary in a particular location does not preclude the possibility of finding them elsewhere," and therefore, such failure does not disprove a hypothesis about their later extinction. Currie and Turner (2017) offered a more nuanced approach: Some inferences from absence are more reasonable than others. They discuss the cases of the coelacanths, ancient fishes that were considered extinct because their traces disappeared from the fossil record 66 million years ago, but were spotted alive in the 20th century. Obviously, an inference from absence was faulty in this case. On the other hand, it is highly plausible that the lack of evidence of extant Pterodactyls (oddball "sightings" notwithstanding) is due to the fact that these Jurassic flying reptiles perished long ago.

ii. Discussing inference from absence in geology, Watson (1982) stated that inference for a geologic removal process can only be valid "if the argument is coupled with further evidence that the rocks were in fact once there" and therefore "one cannot assume from the absence of something that it never was there." Clealand (2016) applied similar reasoning to reject a hypothesis that drumlins (a certain type of landforms) were all created by the same process. Even though no evidence exists for other ways of formation, this absence "cannot be used to justify the conclusion that there is only one way of making it. Additional justification is required."

iii. In Historiography the question of "inference from silence"that is, inferring that an event did not happen because it is never mentioned in any historical document-received much, and generally negative, attention. Newall (2009) denounced it as "the fallacy of negative proof." Henige (2006) pointed out that "A past event has to be witnessed, then the observations recorded, the record preserved for varying periods of time, then found, and finally understood. ... the degree of disappearance has been phenomenally high." A lot of historical evidence, therefore "cannot realistically ever become available" and argument based upon their absence is "fatally weak." These observations serve as a starting point for a Bayesian analysis by McGrew (2014), discussed in section "A probabilistic model" below.

The aversion to inference from absence is not confined to historical science. The century-long search for the detection of gravitational waves (Waldrop, 2016), for example, was not deterred by many negative (or refuted) results. It was the search for extraterrestrial life which motivated Rees and Sagan to state that "absence of evidence is not evidence of absence," and articles making use of this adage to argue for the inconclusiveness of negative evidence can be found in scientific literature ranging from medicine (Altman and Bland, 1995) to astronomy (Cooper et al., 2010).

Scientific versus quotidian inference from absence. It is useful to juxtapose this negative attitude with the high tolerance for inference from absence in everyday life. We are convinced that there were no WMD in Iraq. Noticing that the morning grass is dry, we assume that the night was rainless, etc.

Several philosophers attempted to vindicate inference from absence by pointing to circumstances under which it may be correct or at least plausible. Two lines of thoughts in this direction, independent but convergent in their main conclusions, were developed by Walton (1992, 1996) and by Goldberg $(2010,2011){ }^{8}$ The main point in both these approaches is the following: Such inference is plausible if, or to amount that, the one making it is in the position to say (paraphrasing Goldberg, 2011) "If it were true, I would have had good evidence for it by now." The inference from absence of evidence is reasonable only if the evidence is highly expected. ${ }^{9}$ This seemingly simple condition, called "epistemic closure" and "epistemic coverage" by Walton and Goldberg, respectively, is the key to differentiating between situations where inference from absence is warranted and those in which it has low plausibility.

In many circumstances of scientific research, however, claims of the type "if $\mathrm{P}$ were true, we would have ample evidence to it. Therefore, $\mathrm{P}$ is probably false" cannot be justified.

Historiographers (Henige, 2006; Newall, 2009) recognise that the lack of reference to something in extant texts can happen for many reasons-past writer might not have bothered to mention it, ${ }^{10}$ written materials could have been lost or destroyed, etc.-and therefore does not prove, or even give much support to, the assumption that it did not happen. Geologists (Watson, 1982) reckon that multiple destructive processes-subduction, erosion, uplift, volcanism, etc.-shaped the earth's crust so that the absence of a particular feature can seldom be casually indicative. For evolutionary biologists and palaeontologists, the rareness of fossils implies that the absence of evidence for a species does not prove that it did not exist. ${ }^{11}$ Finally, the large dimensions and complexity of outer space dictate that our epistemic coverage (sensu Goldberg) is unavoidably limited; hence Sagan's (Sagan and Druyan, 1997) criticism of "impatience with ambiguity" with Rees' dictum mentioned above.

That is why arguments and inferences from absence are rare in the sciences (including, for that matter, historiography) even though they are fairly common in everyday discourse.

Archaeology, as demonstrated in the previous section, is an exception in this respect: Archaeologists often posit, consider, and accept inferences from the absence of evidence, on par with inferences from tangible evidence. The next section explains why this is so, and the following one supports and expands this analysis with a quantitative model.

\section{The distinctiveness of archaeology}

Given the prevalence of inference from absence in archaeology, in absolute terms and certainly in comparison to other sciences, it is surprising that the question of its epistemic justification was not examined so far. Treatises on the philosophy of archaeology like Salmon (1982), Wylie (2002), and Chapman and Wylie (2016) do not discuss it. In the more general context of the historical sciences, the perception of inference from absence is, as we saw in section "Why science (usually) won't take no for an answer", largely unfavourable.

The ability of archaeology to reason from absence of evidence stems from the coincidence of two factors, which are closely related to the nature of archaeology as a science that explores the human past via the discovery and interpretation of its surviving material remains. These factors are (1) the strong footprint of human existence and (2) the high degree of survivability (over the relevant timescale) of many types of human material remains.

These factors and their implications are discussed below, and a simplified mathematical model thereof is presented in the next 
section. Their combined effect is that for many issues of interest to archaeologists a claim of the type "if $\mathrm{P}$ were true, we would have evidence for it" can be justified. As discussed in the previous section, under such circumstances inferences from absence have an epistemic standing that is comparable to other empirical inferences.

i. Human presence has a strong and distinctive footprint: All living species perturb their environment, but people-ever since the earliest members of the genus Homo-do something more: they produce, use, and discard plenty of artefacts of all kinds. Foley and Lahr (2015) estimated that during the period of stone tool evolution humans were producing between 10 and a 100 stone tools per person per year, with each production accompanied by a débitage of many detectable (larger than $2 \mathrm{~cm}$ ) flakes. Citing a survey of a region of central Sahara, they report an average density of 75 artefacts per square meter.

A footprint is not only a matter of quantity but also of distinctiveness. Except perhaps to the very earliest human stone tools, which were claimed to resemble natural (Barnes, 1939) or monkey-made (Proffitt et al. 2016) flakes, human artefacts are usually dissimilar enough from their environment to make them easily discernible to the trained eye of the archaeologist.

Later stages of human evolution brought an everincreasing demographic growth, technological advancement, and societal development, with the concomitant result of stronger and more localised footprints. To cite just one example, the transformation from small mobile groups typical to the upper Palaeolithic to sedentary groups in the Natufian culture resulted in localities with concentrations of masonry and lithic artefacts significantly higher than in the previous eras (Belfer-Cohen and Goring-Morris, 2011). This trend of intensification in the number, diversity, and concentration of human material remains continued in subsequent periods.

The development of human cognitive capabilities also tended to increase the distinctiveness of human artefacts, both in the sense of making them dissimilar from the environment and in making style and technology more idiosyncratic, enhancing not only the human footprint per se but also the possibility to associate artefacts with their past users.

ii. Many types of human material remains have high survivability: Human artefacts produced from inorganic materials, though not totally unperishable, have a reasonable chance of leaving material traces that will withstand the elements of nature and destruction by humans. Even mud-brick constructions often survive, and things made of stone, bone, ceramic, or metal usually fare better. (As for organic residues, see section "Limitations of archaeological inference from absence" below.)

To use Currie's (2018, p. 125) terminology, many archaeological traces are neither particularly "gappy" (because a high proportion of the original stuff, abundant in itself, is likely to survive) nor very "faint" (because the traces are distinct and stable midrange theories ${ }^{12}$ to interpret them exist). Research circumstances, including the methodology and technology employed, determine what proportion of human traces can be retrieved by archaeologists.

Archaeological argumentations from absence are sometimes questioned by pointing to the possibility of complete removal of human traces by post-depositional natural erosion or human activities. Interestingly and unlike what normally happens in other sciences, in archaeology it is usually the rebuttal of inference from absence which needs to be specifically supported by pointing to special environmental or historical circumstances that could produce such an effect. For example, when archaeological excavations failed to discover the remains of a biblical $\mathrm{Ai}$ and the walls of Jericho, the possibility of total post-depositional removal was suggested but was generally regarded as ad hoc and unconvincing. ${ }^{13}$

To conclude, it is the combination of two features-human origin and physical nature-of their evidentiary stuff, that create situations in which inferences from absence of evidence have a respectable plausibility. Not all questions of interest to archaeologist fall under this category (cf. section "Limitations of archaeological inference from absence" below), but many important ones do.

Archaeological inferences from absence are particularly effective when applied to questions of the type "who/what was here and when" which are central to much of the archaeological thinking. A sedentary or semi-sedentary human presence can be expected to result in a large number of discernible material remains at their site of living. Therefore, when a systematic and extensive search fails to discover such remains (of a particular period), this constitutes plausible evidence from absence that the site was uninhabited during this period. If traces of earlier and/or later periods are found there, an inference of terminus ad quem/ post quem may be derived. As the examples in section "Inference from absence in archaeology" demonstrate, this can sometimes have the effect of a "smoking gun" (Cleland, 2002, 2011, 2013): a previously unexpected signal that makes the total body of evidence better explained by one hypothesis about the past than by others.

The problem of "evidentiary noise" and inference from paucity. Even when archaeological traces survive, their context may change: Post-depositional processes such as erosion and human activity can dislocate traces from their original context. Orton and Hughes (2013, p. 222) warned archaeologists that

A point which is so obvious that it may seem not worth making is that the date of a pot or a sherd is not necessarily the date of the archaeological context in which it was found. ... Between its original breakage and discard and its final resting place, it may have undergone several events (such as sweeping-up, removal to a rubbish pit, disturbance of that pit, and so on) ... There are thus two potential problems: sherds which are later than their context (intrusiveness) and sherds which are older than their context (residuality) ... it is something of which anyone working with archaeological ceramics should be acutely aware.

In other words, archaeologists must consider the possibility that they will also encounter some false positive evidence or "noise" in the form of traces that "should not have been there." This is a situation that many discussions of inference from absence neglect, but as the citation above shows, is part and parcel of archaeological reality.

Usually, out-of-context traces can be assumed to be few and far between. This is the rationale behind the archaeological practice of considering singular, out-of-context finds (as in examples (iii), (iv) and (vii) in section "Inference from absence in archaeology") as outliers, treating paucity of evidence as lack thereof. This practice may be justified in some circumstances and erroneous in others, as discussed below.

\section{A probabilistic model}

Formal probabilistic approaches were applied to the problem of inference from absence by several scholars, each focusing on a specific context. Oaksford and Hahn (2004) formulated Walton's theory in Bayesian terms using reasoning about drugs' safety as 
an example. Sober (2009) applied likelihoodist analysis in the context of palaeontology and evolutionary biology, exploring the validity of inferring separate ancestry of two lineages from the failure to find an intermediate fossil. Sober's model was discussed by Strevens (2009) and used by Forber and Griffith (2011) to enquire whether the disappearance of a genus from the fossil record can indicate the time of its extinction. Stephens (2011) used Bayesian analysis to show that under some assumptions inference from absence may be plausible ${ }^{14}$, and McGrew (2014) examined inference from silence in historiography (the inference that something that is not mentioned in extant sources did not happen) through Bayesian analysis.

Notwithstanding their dissimilarities, these treatises share two results: First, contrary to the Rees/Sagan maxim, absence of evidence is some evidence for absence. ${ }^{15}$ Second, it is usually very weak evidence, and therefore inference from absence will usually be inconclusive.

To show why in archaeological research the second result often does not hold, I will use a model tailored on Sober's, referring to McGrew's version when relevant. The analysis in this section will also elucidate the rationale behind the archaeological practice of inferring from paucity, mentioned above. The following section points to circumstances in which archaeological inference from absence can be problematic or totally unwarranted. Finally, Section "Only in archaeology?" looks for situations favourable for inference from absence in other historical sciences.

Site excavation. Let us consider first the following common situation: Archaeologists try to determine whether a site was inhabited during a particular period by excavating there and looking for traces (human material remains) from that period. For this example, it is assumed that the putative human presence of the site was substantial and relatively long (a generation or more).

Modern archaeological excavation is a planned undertaking, in which the area to be explored is parcelled into small units. Each square is then slowly and meticulously exposed, and an attempt is made to extract and record every single artefact; techniques like sieving and flotation are sometimes used for better recovery.

Definitions and notations. Let $\mathrm{H}$ denote the hypothesis that the site was inhabited at the relevant period and $\sim \mathrm{H}$ the hypothesis that it was not. $\mathrm{E}$ is the event of finding relevant evidence supporting $\mathrm{H}$, and $\sim \mathrm{E}$ the event of finding none.

Let $p$ be the likelihood that an adequate trace exists in the site, assuming it was indeed inhabited. Because of the strong human footprint and the good survivability of many types of human material remains, discussed in the previous section, a site that was inhabited by humans for an appreciable time is expected to contain many human artefacts. We shall therefore initially assume, like Sober, that $p=1$ (this assumption shall be modified later).

Let $q$ be the likelihood that a stray trace from the same period exists in the site even though the site was not inhabited during the period in question. This "noise" probability can be the result of post-depositional processes that, as the citation form Orton and Hughes above shows, cannot be neglected in archaeological research. ${ }^{16}$

Finally, let $\alpha$ be the probability of detecting a trace (if such exists). Following Sober (2009, 71 8n) and Strevens (2009, p. 99) we can assume that the existence of a trace "screens off" its discovery from the competing hypotheses. That is, the detection probability $\alpha$ is a function of the technology and the research method applied but independent of whether the site was or was not inhabited during the relevant period. ${ }^{17}$ The likelihood of finding an appropriate trace in the site, then, equals $\alpha$ if the site was occupied and equals $\alpha \cdot q$ if it was not. The likelihoods of not finding one are $1-\alpha$ and $1-\alpha \cdot q$, respectively.

The strength of inference from absence ${ }^{18}$-that is, of inferring $\sim H$ from $\sim E-$ is measured by the likelihood ratio: $P(\sim E \mid \sim H) / P$ $(\sim E \mid H) .{ }^{19}$ The higher the ratio, the safer the inference.

Let $R^{-}$denote this ratio. Using the notations above, we get

$$
R^{-}=(1-\alpha q) /(1-\alpha)
$$

Sober as well as Forber and Griffith discuss situations, typical to palaeontology, where $\alpha$ is low. Indeed, finding fossilised specimen, especially one of a "missing link" or rare genus, is difficult; that is why such discoveries get front-page coverage. Under such circumstances, the likelihood ratio (for any value of $q$ ) is a little greater than one. For example, if $\alpha=0.1$ and $q=0.1$ (as in Forber and Griffith, 2011, 14n) one gets $R^{-}=1.1$. The inference from absence has some force since the likelihood ratio $R$ - is greater than one, but it is weak and inconclusive. In Currie's (2108) words, an absence of fossils can be a geological signal, revelatory of fossilisation and preservation processes, rather than a biological signal informative about life's history.

For an orderly archaeological excavation, however, the probability of detecting a trace, if such exists in the site, is significant because such traces are easily distinguishable and the search is localised and intensive. For $\alpha=0.8$ and $q=0.1$, for example, we get $R^{-} \approx 5$. Increasing the probability of detection (for example through the use of sieving) will result in higher values of $R^{-}$. Under such circumstances, inference from absence cannot be discarded as inconclusive but must be considered as any other empirical inference.

McGrew (2014, p. 221), discussing evidence from absence in historiography, even notes that since $R^{-}$can be written as $P(\sim E \mid$ $\sim H) /[1-P(E \mid H)]$ "there is no limit on the strength of argument from silence" because when $E$ is very probable under $H$ the denominator approaches zero. As he convincingly shows, however, for historiographic texts $P(E \mid H)$ will typically be small -there are many possible causes for an event not to get mentioned in the extant documents and therefore in historiography "the argument from silence will have very little force."

Before going further, it is worth recapping what was shown so far: Models (Sober, 2009; McGrew, 2014) created to demonstrate that inference from absence of historical traces is weak and inconclusive, show that under conditions typical to archaeological excavations such inference can have a respectable plausibility.

Absence and objectivity. Strevens (2009), commenting on Sober, offers an alternative analysis: The absence of evidence is (typically) not epistemically objective evidence of absence, and therefore unacceptable in scientific reasoning. Epistemic objectivity comes in degrees, and Strevens' measure for the objectivity of evidence is proportional to the objectivity of the relevant likelihoods, or of their ratios. The more their values depend on the probabilities of auxiliary hypotheses, which different scientists may asses differently, the less objective they are.

Strevens observes that evaluating the likelihood of a separate ancestry of two lineages from the failure to find an intermediate fossil involves making a lot of assumptions about the past geographical distribution of all possible intermediate species and their chances of fossilisation and preservation. The value of the likelihood ratio $P(\sim E \mid \sim H) / P(\sim E \mid H)$ for separate ancestry hypothesis, therefore, will be highly subjective and the inference from absence will be of inferior value. ${ }^{20}$

Things are different for a regular, systematic archaeological excavation that seeks to answer the question "Was this site occupied at the period T?" or a similar one. As explained above, 
we are concerned with situations in which the probability of discovering a trace (if such exists) is high and the probability of the existence of traces given past inhabitation is very high. Under such conditions, there would not be many "excuses" (explanations based on auxiliary hypotheses) for not discovering any trace in a previously inhabited site, and the inference from absence would be reasonably objective. Stated differently, an epistemic community that accepts (as most archaeologists would certainly do) that human footprint is usually strong and many of its traces are distinct and therefore retrievable would accept an inference of $\sim H$ as objective (though defeasible) whenever the search is sufficiently intensive and returns negative results.

Surface foot-walking survey is another method of archaeological research for discovering and identifying traces of past human settlements. Here, however, the probability of detection is usually lower. If we assume $\alpha=0.2$ (the lower value mentioned by Banning et al. (2017) for a transect of $\pm 2 \mathrm{~m}$ ), ${ }^{21}$ we get (with $q$, as before, 0.1$) R^{-} \approx 1.25$.

This indicates that Inference from absence from a single survey sweep is not well supported. Appropriately, Banning (2002, pp. 204-205) warns that "just because a survey finds no artefacts diagnostic of some other period does not ensure that the site was unoccupied during that period."

Uncommon traces, common false traces and the inference from paucity. It was assumed above that that if a site was occupied in the period of interest, the probability of human material remains being there is unity. This approximation is adequate for mundane artefacts, such as sherds of domestic vessels, which should be present in great quantity if the site was inhabited for an appreciable time. But archaeologists sometimes look for rare but highly indicative traces, for example when the dating of the site's occupation is in doubt.

Let $p$ (now, smaller than one) be the probability that such rare traces exist in the explored site if it was inhabited at the relevant period; the likelihoods of finding and missing it, therefore, equal $\alpha \cdot p$ and $1-\alpha \cdot p$, respectively. The corresponding likelihoods of "noise detection" if the site was unoccupied at the relevant period are, as before, $\alpha \cdot q$ and $1-\alpha \cdot q$.

The likelihood ratio for the inference from absence becomes:

$$
R^{-}=P(\sim E \mid \sim H) / P(\sim E \mid H)=(1-\alpha q) /(1-\alpha p)
$$

where $E$ now means "finding just a single (or very few) rare and indicative traces." Here, however, we must also consider the strength of a positive inference. How certain can we be, finding a single rare trace, that the site was occupied in the relevant period? Denote the appropriate likelihood ratio by $R^{+}$:

$$
R^{+}=P(E \mid H) / P(E \mid \sim H)=p / q
$$

The support for both a positive inference given a find and for a negative inference after none was found is smaller than when traces are very abundant, and $p$ practically equals one. ${ }^{22}$ Both ratios approach unity when $p$ gets closer to $q$, the background probability of archaeological "noise." This is one reason why archaeologists often regard a single exceptional trace (as in example (iv) in section "Inference from absence in archaeology") as inconsequential.

Another situation in which the discovery of just a few traces can be equivocal is when the "noise" is expected to be significant (in our model, this corresponds to a relatively high value of $q$ ). Cereals might have been imported to the Indian subcontinent, and wild camels roamed the Levantine deserts, before they were domesticated there (examples (iii) and (vii) in section "Inference from absence in archaeology"). The probability of encountering remains from these pre-domestication phenomena cannot be assumed to be negligible.
Increase in the value of the "noise probability" $q$ diminishes both $R^{+}$and $R^{-}$, but not in the same amount. In fact, for high values of $q$ (and of $\alpha$, as typical for archaeological excavations) the negative inference, given a single piece of evidence, may be better supported than the positive one. ${ }^{23}$ This simple reasoning explains why Fuller, Ben Yosef and Hen-Sapir, and many other archaeologists often treat paucity of evidence as practical absence, drawing an inference from absence thereof.

If we demand that the number of relevant traces found exceeds a specified minimum then the likelihoods, expressed in cumulative distributions and their complementary functions, will be too complicated to capture in the simple formalism used here. But the following will be generally true: An increase in the "cutoff number" of relevant traces required for a positive inference (i.e., that the hypothesis under research is true) will make the positive inference stronger and the negative one less secure. This can result in a false negative inference.

\section{Limitations of archaeological inference from absence}

At the risk of stating the obvious, let me stress that even under the best conditions inference from absence will just be an (abductive) empirical inference, and as such defeasible by future evidence or analysis. (This, of course, only puts it on par with "regular" inference from positive evidence).

In particular, one must be aware that the justification for inference from absence, as outlined above, is essentially local since it rests on the failure to find sought-after evidence in an intensive localised search. ${ }^{24}$ A generalisation from the local to the globalfrom the excavated area to the whole site, from several sites to a territorial unit or worldwide-constitutes, logically speaking, an additional inference that needs to be examined in itself and can be called into question by findings from other localities.

For example, the "Clovis hypothesis" about the date and route of human arrival in the Western Hemisphere was for many years supported by the absence of evidence for human activity in the Americas before 13,500 years ago in many researched localities in the Western Hemisphere. Recent discoveries (Goebel et al., 2008; Holen et al., 2017), have, however, strongly challenged this hypothesis. Similarly, evidence for extinction of the ammonites before the Cretaceous-Paleogene boundary, gathered from one locality, was overturned by results from other places. (Ward, 1990, p. 427; see also Cleland, 2013).

There are also some questions of interest to archaeologists in which such inference would of be limited applicability, or entirely unwarranted. Below are several salient examples:

i. Organic materials, being degradable, cannot be assumed to leave the strong footprint necessary for inference from absence. Therefore, when archaeologists (as in examples (i) and (iii) in section "Inference from absence in archaeology") hypothesise from the absence of organic material remains, they usually stress that their inference is based on a very large sample, comprising many pieces of (negative) evidence. Many artefacts of biological and botanical origin (e.g., papyri) will survive only under exceptional circumstances, and their absence cannot, therefore, support an inference.

ii.The Archaeology of Nomads: Due to their high mobility, low population density, and transient camping, nomads are often difficult to identify archaeologically. As Finkelstein and Perevolotsky (1990) write:

The nature of nomadism accounts for the dearth of material remains. ... the constant migration permits them to move only minimal belongings. Moreover, their limited resources do not facilitate the creation of a flourishing material culture that could leave rich archaeological finds. 
Ben-Yosef (2016) adds that even complex, stable and relatively affluent nomadic societies "unless engaged in unique activities such as mining and smelting, are transparent in common archaeological practice." Despite the considerable progress in the "archaeology of mobility" (Barnard and Wendrich, 2008) sites of nomads may evade detection. As Smith (2008) reports:

Extensive surveys for Kohe sites have been carried out, even in areas that they were reported in historical literature ... but none have been found. We have to accept that their archaeological "invisibility" must be due to their mobility and transience across the landscape.

Apparently, not much can be adduced from not finding traces under such circumstances, and inference from absence cannot be justified.

ii. Questions of identity: The ethnic or social identity of past people is often not distinguishable in their material remains. "Even in situations characterised by a high degree of homology between the habitus and ethnicity, archaeologists may not be able to find 'ethnic entities' reflected in material culture distributions." (Jones, 1997, p. 12). Na'aman (1994) discussed the hypothesis that northern ("Hurrian") people migrated into Palestine at the end of the Middle Bronze II. This hypothesis is supported by distinctive names mentioned in cuneiform tablets unearthed in Palestine and Egypt, but by only a few, if any, material remains. He concludes, therefore, that "Archaeological evidence may corroborate the presence of such groups, but lack of positive evidence is not enough to deny migration to a certain place."

Even in the rare cases in which a clear absence of a particular identity trait can be demonstrated, the question of what this absence is evidencing is not easily settled, as shown by example (vi) in section "Inference from absence in archaeology" above. Similarly, the lack of pig remains in some locations of Iron-Age Palestine was interpreted as an indication of an Israelite population but is now considered insufficient to support such an inference (Hesse and Wapnish, 1997; Sapir-Hen et al., 2013).

i. iii Cultural/Cognitive traits and abilities of past people are only partially and contingently reflected in their material artefacts. The ability of "cognitive archaeology" to illuminate them is a matter of contention (Renfrew, 1998; Hodder, 2012), but it is clear that evidence-from-absence arguments would not be helpful in this context. For example, while grave goods are typically interpreted as an indication of a belief in the afterlife, their absence (e.g., in tombs of early Christians) cannot support a contrary hypothesis.

The list above is not meant to be exhaustive. Archaeological inference from absence, while having a reasonable validity when used to probe questions of the type "who was here when" in the context of sedentary sites and systematic excavation, has a weaker power in other research circumstances (e.g., field survey) and none at all when the human material footprint is weak or equivocal.

\section{Only in archaeology?}

For Inference from absence to be plausible, the expectancy of finding evidence (assuming the existence of the searched-for phenomenon) should be high. This usually means that both the probability of existence of evidence $(p)$ and the probability of its detection $(\alpha)$ are high.

As shown above, the combination of abundance, survivability (over the relevant time-scale) and distinctiveness of many types of human material artefacts can create favourable circumstances for archaeological inference from absence. Looking for similar situations in other historical sciences, two potential categories can be outlined:

i. Broad questions: When the question of interest is quite general and refers to a wide swath of time and/or geography, it may be reasonable, following an appropriate search, to consider the absence of evidence as (tentative) evidence for absence. If no traces of flowering plants were found in Devonian sediments worldwide, probably none existed then.

ii. For more precise and detailed questions, undisturbed-or only lightly disturbed-assemblages of abundant traces may be our best candidates of inference from absence. For example, Ward (1990), discussing the problem of determining extinction dates from the fossils record, noted that:

The documented ranges of small, common, and readily collected species are going to be closer to their actual ranges than are the observed ranges of rarer species. A corollary of this is that rarer species will require far more effort in collection than will the more common species if reliable range charts are to be determined.

Forber and Griffith (2011, p. 12) also remarked that the disappearance of high-abundance traces like pollens and foraminiferans from the fossil record, unlike that of other species, provides strong support for inferring the time of their extinction.

In historiography, inference from absence based on intact archives, especially ones of mundane bureaucratic records, can have a decent plausibility. Similar situations can be sought in other historical sciences.

For reasons discussed in section "Why science (usually) won't take no for an answer", these situations are the exception rather than the rule in most scientific disciplines, which explains why scientific arguments and inferences from absence are uncommon.

\section{Conclusion}

It is a demonstrable fact that inference and reasoning from absence are common in archaeology, often enjoying a status on par with other empirical inferences. Archaeologists are usually not aware that this practice is at variance with other scientific disciplines.

Our purpose here was to examine if, or under what conditions, this practice can be epistemically justified. The analysis presented above showed that the strong footprint that characterised human communities since early prehistory, combined with the high survivability and distinguishability of many human artefacts, can create situations where archaeologists can reasonably expect to find evidence of past human presence if such existed. Under such circumstances, inference from absence is plausible. When combined with midrange theories like typology and stratigraphy that connect archaeological traces to the time and circumstances of their creation, such negative inferences can factor in the reconstruction of human history no less than positive inference from tangible traces.

The examples and discussion above show that such circumstances obtain in common and important parts of archaeological work. In other sciences, similar situations are rare, though not inconceivable. The analysis offered here can point to potential candidates.

There are, however, several types of archaeological research questions in which inference from absence is problematic or totally unwarranted because the conditions required to justify it are not met. And even when the archaeological inference from 
absence is reasonably secure, the generalisation from local absence to global inference must be justified separately.

Archaeologists, as well as historiographers who reason from their results, must be cognizant of both the justification and the limitations of archaeological inference from absence.

\section{Data availability}

Data sharing not applicable to this article as no datasets were generated or analysed during the current study.

Received: 29 May 2019 Accepted: 30 July 2019

Published online: 20 August 2019

\section{Notes}

1 I shall be using "inference from absence" except when quoting from sources that use one of the other terms.

2 Inference from absence should not be confused with eliminative inference. In the latter, intransigent results-either positive or negative-that cannot be explained by available hypotheses, motivate the formulation of a novel one. Unlike inference from absence, instances of eliminative inference appear in all sciences (cf., e.g., Kitcher, 1993, p. 237ff.)

3 The phrase was originally coined by the astronomer Martin Rees.

4 "Rabi Hanina, vice chief of the priests, said: All my days I never saw a hide taken out to the place of burning...But the sages say: 'We saw not' is not a proof, and [such a hide] must be taken to the place of burning" (Mishna/Nezikin/Eduyot Ch. 2).

5 In one case cited, "there were only 13 grains of barley compared to 3000 grains of small millets."

6 A secondary argument was the absence of Egyptian-style pottery from strata in Philistine settlements.

7 Forber and Griffith (2011) seem to share Turner's pessimistic view, while Cleland $(2002,2011)$ and Jeffares (2010) maintain a more sanguine opinion about the prospects of retrieving and interpreting traces of past events and states-of-affairs. Tucker (2011) offers a context-dependent analysis and Currie $(2015,2018)$ stresses the possibilities of reasoning about the past that do not involve direct inference from traces.

8 Pedersen and Kallestrup (2013) expanded Goldberg's analysis from the alethic to the evidential context.

9 Carrier (2012, p. 217) makes a similar point in regard to evidence for the historicity of Jesus.

10 For instance, two detailed reports on the eruption of the Vesuvius, written by Pliny the Younger for Tacitus, do not mention the destruction of Pompeii and Herculaneum. McGrew (2014) has more examples.

11 That is, did not exist when they could have existed. We are confident that pterodactyls perished because their natural habitat (unlike that of the coelacanths) makes is very unlikely that they still existed today and, more importantly, that if they were than "we should have had (verifiable) evidence for it by now."

12 Chapman and Wylie (2016) prefer to speak of "warranting assumptions or, more broadly ... the scaffolding on which archaeologists rely to identify and mobilize data as evidence." It is the iterative, scaffolding-like employment of data and auxiliary hypothesis, they stress, that creates " the capacity of surviving traces to bear witness to pasts that are otherwise unimagined or unimaginable."

13 Compare this to McGrew (2014, p. 228) assertion that "Anyone who puts forward an argument from silence in historical enquiry should offer explicit arguments for each of the three claims..." (that the events or facts in question would have been noticed and recorded at the past and that the records would have survived and come to notice today).

14 Interestingly, Stephens mentioned archaeology as a discipline that makes use of arguments from absence. He does not elaborate, however, nor gives any specific examples.

15 This follows simply from the mathematical truism that if evidence is more likely under a particular hypothesis than under its negation, than the opposite is true for the lack of such evidence (Strevens, 2009, p. 93).

16 "False positives" signals are considered by Sober and Forber and Griffith, but not by McGrew (probably because he considers the possibility of encountering a falsified historical document negligible).

17 Strictly speaking, this "screening off" assumption is an approximation. The approximation is reasonable, however, under most circumstances, and modifying it would complicate the analysis without changing the qualitative result.

18 The appropriate measure for the degree of confirmation of hypotheses by evidence is a matter of debate (Eells and Fitelson, 2000; Sober, 2008, pp. 16-74; Zalabardo, 2009).
I believe that, at least for the situations discussed below, the likelihoodist framework is the most useful.

19 This is something on which all the sources cited above agree. For Bayesians, this factor modifies the ratio of prior probabilities $P(\sim H) / P(H)$ (Salmon, 1990, pp. 191-192), while likelihoodist avoid discussing priors and regard the likelihood ratio as a measure of confirmation.

20 Strevens shows (pp. 98-99) that under the screening-off approximation mentioned above a similar problem does not exist when computing the strength of "positive" inference (inferring common ancestry from evidence for a particular intermediate form).

21 Search strategies developed to increase the probability of detection such as repeated sweeps, crew selection, and training enhance probability of detection and with it the security of inference from absence.

22 If $p=1$ the strength of the positive inference will be inversely proportional to "noise" probability of stray traces.

23 Example for $q=0.5, \alpha=0.8$ and $p=1, R^{+}=2$ and $R^{-}=3$

24 Cleland (2011, p. 20) posits that all inferences and explanations in the historical sciences are primarily local. Sober (1988, p. 123) defends a similar idea (concerning in particular parsimony assumptions) and Norton (2003) maintains that all inductive inference is local.

\section{References}

Albright WF (1940) From stone age to Christianity, Monotheism and the historical process. John Hopkins Press, Baltimore

Albright WF (1968) Yahweh and the gods of Canaan, A historical analysis of two contrasting faiths (vol. 7). Eisenbrauns, University Park, Pennsylvania

Altman DG, Bland JM (1995) Statistics notes, Absence of evidence is not evidence of absence. Br Med J 311(7003):485

Banning EB (2002) Archaeological survey. Kluwer Academic/Plenum Publishers, New York

Banning EB, Hitchings AL, Stewart ST, Hitchings P, Edwards S (2017) Quality assurance in archaeological survey. J Archaeol Method Theory 24(2):466-488

Barnard H, Wendrich W (2008) The archaeology of mobility. Cotsen Institute of Archaeology, The University of California, Los Angeles

Barnes AS (1939) The differences between natural and human flaking on prehistoric flint implements. Am Anthropol 41(1):99-112

Bar-Yosef O, Belfer-Cohen A (2001) From Africa to Eurasia-early dispersals. Quat Int 75(1):19-28

Belfer-Cohen A, Goring-Morris AN (2011) Becoming farmers: the inside story. Curr Anthropol 52(S4):S209-S220

Bellwood P (2005) First Farmers; The Origins of Agricultural Societies. Blackwell, Malden

Ben-Tor A (2006) Do the execration texts reflect an accurate picture of the contemporary settlement map of Palestine? In: Amit Y, Ben Zvi E, Finkelstein I and Lipschits $\mathrm{O}$ (eds) Essays on ancient Israel in its near eastern context, a tribute to Nadav Na'aman. Eisenbrauns, University Park, Pennsylvania, pp. $63-87$

Ben-Yosef E (2016) Back to Solomon's Era, results of the first excavations at Slaves' Hill (Site 34, Timna, Israel). Bull Am Sch Orient Res 376:169-98

Callaway JA (1968) New evidence on the conquest of Ai. J Biblic Lit 87(3):312-320

Carrier RC (2012) Proving history, Bayes's theorem and the quest for the historical Jesus. Prometheus Books, Amherst

Childe VG (1934) New light on the most ancient East, the oriental prelude to European prehistory. Routledge and K. Paul, London

Chapman R, Wylie A (2016) Evidential reasoning in archaeology. Bloomsbury Publishing, London

Cleland CE (2002) Methodological and epistemic differences between historical science and experimental science. Philos Sci 69(3):447-451

Cleland CE (2011) Prediction and explanation in historical natural science. Br J Philos Sci 62(3):551-582

Cleland CE (2013) Common cause explanation and the search for a smoking gun. In: VR Baker (ed) Rethinking the Fabric of Geology: Geological Society of America Special Paper 502, The University of Arizona, Tucson, Arizona, pp. 1-9

Clealand CE (2016) Traces from the past-Drumlins. http://www.extinctblog.org/ extinct/2016/3/14/18vx759zkrz8jdm86uq3h5pmyiaued?rq=carol\%20cleland

Cooper MC, Coil AL, Gerke BF, Newman JA, Bundy K, Conselice CJ, Koo DC (2010) Absence of evidence is not evidence of absence: the colour-density relation at fixed stellar mass persists to $\mathrm{Z} \sim 1$. Mon Not R Astron Soc 409 (1):337-345

Copi IM (1953) Introduction to logic. Macmillan, New York

Currie A (2015) Marsupial lions and methodological omnivory: function, success and reconstruction in paleobiology. Biol Philos 30(2):187-209

Currie A (2018) Rock, bone, and ruin: an optimist's guide to the historical sciences, Kindle edition. MIT Press, Cambridge, Massachusetts

Currie A, Turner D (2017) The missing fossils matter as much as the ones we have found. https://aeon.co/ideas/the-missing-fossils-matter-as-much-as-the-oneswe-have-found 
Elles E, Fitelson B (2000) Measuring confirmation and evidence. J Philos 97 (12):663-672

Finkelstein I (1995) The date of the settlement of the Philistines in Canaan. Tel Aviv 22(2):213-239

Finkelstein I, Perevolotsky A (1990) Processes of sedentarization and nomadization in the history of Sinai and the Negev. Bull Am Sch Orient Res 279:67-88

Foley RA, Lahr MM (2015) Lithic landscapes, early human impact from stone tool production on the central Saharan environment. PLoS One 10(3):e0116482

Forber P, Griffith E (2011) Historical reconstruction, gaining epistemic access to the deep past. Philos Theory Biol 3(201306):1-19

Fuller DQ (2006) Agricultural origins and frontiers in South Asia, a working synthesis. J World Prehistory 20(1):1-86

Garstang J (1931) The foundations of Bible history, Joshua, judges. Constable and Company, London

Goebel T, Waters MR, O'rourke DH (2008) The late Pleistocene dispersal of modern humans in the Americas. Science 319(5869):1497-1502

Goldberg S (2010) The epistemology of silence. Oxford scholarship online

Goldberg S (2011) If that were true I would have heard about it by now. In: Moser PK (ed) The Oxford handbook of social epistemology. Oxford University Press, Oxford, pp. 92-108

Hesse B, Wapnish P (1997) Can pig remains be used for ethnic diagnosis in the ancient Near East? J Study Old Testament Suppl Ser 237:238-270

Henige D (2006) Historical evidence and argument. University of Wisconsin Press, Madison, Wisconsin

Hodder I (2012) Entangled, an archaeology of the relationships between humans and things. John Wiley and Sons, Chichester, United Kingdom

Holen SR, Deméré TA, Fisher DC, Fullagar R, Paces JB, Jefferson GT, Beeton JM, Cerutti RA, Rountrey AN, Vescera L, Holen KA (2017) A 130,000-year-old archaeological site in southern California, USA. Nature 544(7651):479-483

Hublin J, Roebroeks W (2009) Ebb and flow or regional extinctions? On the character of Neandertal occupation of northern environments. C R Palevol 8 (5):503-509

Jeffares B (2010) Guessing the future of the past. Biol Philos 25(1):125-142

Jones S (1997) The archaeology of ethnicity, constructing identities in the past and present. Routledge, London and New York, NY

Kitcher P (1993) The advancement of science, science without legend, objectivity without illusion. Oxford University Press, Oxford

Locke J (1690) An essay concerning human understanding. Hackett Publishing, Cambridge, Massachusetts

López S, van Dorp L, Hellenthal G (2015) Human dispersal out of Africa, a lasting debate. Evolut Bioinforma online 11(Suppl. 2):57-68

Marquet-Krause J (1934) Excavations in Palestine 1933-4. Et-Tell. In: The Quarterly of the department of antiquities in Palestine, vol. IV, Oxford University Press, Oxford, pp. 204-205

Marquet-Krause J (1935) La deuxième campagne de fouilles a Ay (1934). Rapport sommair. Syria 16:325-345

Mazar A (1997) Iron Age chronology, a reply to I. Finkelstein. Levant 29 (1):157-167

McGrew T (2014) The argument from silence. Acta Anal 29(2):215-228

Na'aman N (1994) The Hurrians and the end of the Middle Bronze Age in Palestine. Levant 26(1):175-187

Newall P (2009) Logical Fallacies of Historians. In: Tucker A (ed) A companion to the philosophy of history and historiography (Blackwell Companions to Philosophy), Kindle Edition. Wiley, Chichester, United Kingdom, pp. $262-273$

Norton JD (2003) A material theory of induction. Philos Sci 70(4):647-670

Oaksford M, Hahn U (2004) A Bayesian approach to the argument from ignorance. Can J Exp Psychol 58(2):75-85

Orton C, Hughes M (2013) Pottery in archaeology. Cambridge University Press, Cambridge

Pedersen NJLL, Kallestrup J (2013) The epistemology of absence-based inference. Synthese 190(13):2573-2593

Piper PJ (2017) The origins and arrival of the earliest domestic animals in mainland and island Southeast Asia: a developing story of complexity. In: Piper PJ, Matsumura H, Bulbeck D (eds) New perspectives in Southeast Asian and Pacific Prehistory. ANU Press, Canberra, Australia, pp. 251-273

Proffitt T, Luncz L, Falótico T, Ottoni E, de la Torre I, Haslam M (2016) Wild monkeys flake stone tools. Nature 539(7627):85-88

Renfrew C (1998) Mind and matter, cognitive archaeology and external symbolic storage. In: Renfrew C, Scarre C (eds) Cognition and material culture, the archaeology of symbolic storage. McDonald Institute for Archaeological Research, Cambridge University Press, Cambridge, pp. 1-6

Roebroeks W, Villa P (2011) On the earliest evidence for habitual use of fire in Europe. Proc Natl Acad Sci USA 108(13):5209-5214

Sagan C, Druyan A (1997) The demon-haunted world, Science as a candle in the dark. Random House, New York, NY
Salmon W (1990) Rationality and objectivity in science or Tom Kuhn meets Tom Bayes. Sci Theor 14:175-204

Salmon M (1982) Philosophy and archaeology. Academic Press, New York

Sapir-Hen L, Ben-Yosef E (2013) The introduction of domestic camels to the southern Levant, evidence from the Aravah Valley. Tel Aviv 40 (2):277-285

Sapir-Hen L, Bar-Oz G, Gadot Y, Finkelstein I (2013) Pig husbandry in Iron Age Israel and Judah, new insights regarding the Origin of the 'Taboo'. Z Dtsch Palästina-Ver 129(1):1-20

Smith AB (2008) Is absence of evidence, evidence of absence? Problems in the archaeology of early herding societies in Southern Africa. In: Barnard $\mathrm{H}$ Wendrich W (eds.) The archaeology of mobility, Old World and New World nomadism. Cotsen Institute of Archaeology, University of California, Los Angeles, pp. 264-279

Sober E (1988) Reconstructing the past; parsimony, evolution and inference. MIT Press, Cambridge, Massachusetts

Sober E (2008) Evidence and evolution: The logic behind the science. Cambridge University Press, Cambridge

Sober E (2009) Absence of evidence and evidence of absence, evidential transitivity in connection with fossils, fishing, fine-tuning, and firing squads. Philos Stud 143(1):63-90

Strevens M (2009) Objective evidence and absence, comment on Sober. Philos Stud 143(1):91-100

Stephens CL (2011) A Bayesian approach to absent evidence reasoning. Informal $\log 31(1): 56-65$

Tucker A (2011) Historical science, over-and underdetermined: a study of Darwin's inference of origins. Br J Philos Sci 62(4):805-829

Turner D (2007) Making prehistory: Historical science and the scientific realism debate. Cambridge University Press, Cambridge

Waldrop M (2016) The hundred-year quest for gravitational waves. http://www. nature.com/news/the-hundred-year-quest-for-gravitational-waves-inpictures-1.19340

Walton D (1992) Nonfallacious arguments from ignorance. Am Philos Q 29 (4):381-387

Walton D (1996) Arguments from ignorance. The Pennsylvania State University Press, University Park, Pennsylvania

Ward PD (1990) The Cretaceous/Tertiary extinctions in the marine realm; a 1990. Perspect Geol Soc Am Spec Pap 247:425-432

Watson RA (1982) Absence as evidence in geology. J Geol Educ 30(5):300-301

Wylie A (2002) Thinking from things: essays in the philosophy of archaeology. University of California Press, Berkley and Los Angeles

Zalabardo J (2009) An argument for the likelihood-ratio measure of confirmation Analysis 69(4):630-635

\section{Acknowledgements}

I am grateful to Yemima Ben-Menahem and Yosef Garfinkel for their helpful comments on earlier drafts of this manuscript.

\section{Additional information}

Competing interests: The author declares no competing interests.

Reprints and permission information is available online at http://www.nature.com/ reprints

Publisher's note: Springer Nature remains neutral with regard to jurisdictional claims in published maps and institutional affiliations.

Open Access This article is licensed under a Creative Commons Attribution 4.0 International License, which permits use, sharing, adaptation, distribution and reproduction in any medium or format, as long as you give appropriate credit to the original author(s) and the source, provide a link to the Creative Commons license, and indicate if changes were made. The images or other third party material in this article are included in the article's Creative Commons license, unless indicated otherwise in a credit line to the material. If material is not included in the article's Creative Commons license and your intended use is not permitted by statutory regulation or exceeds the permitted use, you will need to obtain permission directly from the copyright holder. To view a copy of this license, visit http://creativecommons.org/ licenses/by/4.0/

(c) The Author(s) 2019 